\title{
SAÚDE E AMBIENTE: FLUTUAÇÃO DE FANÍDEOS EM CAMPUS UNIVERSITÁRIO EM PRESIDENTE PRUDENTE, SÃO PAULO
}

\section{Lucas de Castro Faria ${ }^{1}$}

Leonice Seolin Dias ${ }^{2}$

Raul Borges Guimarães ${ }^{3}$

\begin{abstract}
RESUMO
Algumas espécies de moscas são vetores mecânicos de fungos, bactérias, ovos de helmintos e cistos de protozoários. Este trabalho tem como objetivo verificar a frequência de moscas varejeiras no campus da Universidade Estadual Paulista (UNESP) de Presidente Prudente, São Paulo. As moscas foram capturadas no período de junho de 2007 a junho de 2008, com capturas semanais, totalizando 40 coletas. Para a captura dos insetos utilizou-se de seis armadilhas confeccionadas com garrafas PET, de $2 \mathrm{~L}$, contendo como atrativo fígado bovino e carcaça de peixe, permanecendo expostas em árvores a uma altura de $1,0 \mathrm{~m}$ a $1,70 \mathrm{~m}$ durante cinco dias. Foram capturadas 146 moscas da família Fanniidae. O ponto de maior captura foi o próximo ao laguinho/cantina com 53,2\%. No verão de 2008 capturou-se $68,7 \%$ dos insetos, seguido do outono de 2008 com 28,9\%, da primavera de $2007 \mathrm{com}$ $2,4 \%$ e no inverno não houve capturas. A análise gráfica relativa ao número de capturas ao longo dos meses sugere a existência de um pico de ocorrência, no meio do verão, indicando a existência de fatores climáticos capazes de regular a proliferação dos fanídeos na região.
\end{abstract}

Palavras-Chave: Campus Universitário; Moscas; Saúde Publica.

\section{HEALTH AND ENVIRONMENT: CANIDS FLOATING ON UNIVERSITY CAMPUS PRESIDENTE PRUDENTE, SÃO PAULO}

\footnotetext{
ABSTRACT

Some species of flies are mechanical vectors of fungi, bacteria, helminth eggs and protozoa cysts. This study aims to determine the frequency of gadflies on the campus of Universidade Estadual Paulista (UNESP) of Presidente Prudente, Sao Paulo. The flies were captured in June 2007 and June 2008, with weekly catches totaling 40 collections. To catch the insects was used six traps made from

${ }^{1}$ Graduando em Geografia, Universidade Estadual Paulista - UNESP, Presidente Prudente, SP: lucas castro faria@hotmail.com.

${ }^{2}$ Doutoranda em Geografia, UNESP, Presidente Prudente - SP: nseolin@gmail.com.

${ }^{3}$ Docente do programa de Pós-graduação em Geografia, UNESP, Presidente Prudente, SP: raul@fct.unesp.br
} 
PET bottles, 2L, containing as attractive beef liver and fish carcass, remaining exposed in trees at a height of $1.0 \mathrm{~m}$ to $1.70 \mathrm{~m}$ for five days. 146 flies Fanniidae family were captured. The point of greatest catch was the next to the pond / canteen with $53.2 \%$. In the summer of 2008 was captured $68.7 \%$ of the insects, followed by the fall of 2008 with $28.9 \%$, the spring of 2007 with $2.4 \%$ and in winter there was no catch. The graphical analysis of the number of catches over the months suggests the existence of a peak occurrence in the middle of summer, indicating the existence of climatic factors capable of regulating proliferation of fanídeos in the region.

Keywords: University Campus; Flies; Public Health.

\section{SALUD Y MEDIO AMBIENTE: CÁNIDOS FLOTANTES EN EL CAMPUS DE LA UNIVERSIDAD EM PRESIDENTE PRUDENTE, SÃO PAULO}

\section{RESUMEN}

Algunas especies de moscas son vectores mecánicos de hongos, bacterias, huevos de helmintos y quistes de protozoos. Este estudio tiene como objetivo determinar la frecuencia de los tábanos en el campus de la Universidad Estadual Paulista (UNESP) de Presidente Prudente, Sao Paulo. Las moscas fueron capturadas em el período de junio de 2007 a junio de 2008, capturas semanales, con un total de 40 colecciones. Para atrapar los insectos se utilizaron seis trampas hechas de botellas de PET, 2L, que contiene como atractivo hígado de res y carcasa de pescado, permaneciendo expuestos en árboles a una altura de 1,0 m hasta $1,70 \mathrm{~m}$ por cinco días. Se capturo 146 moscas de la familia Fanniidae. El punto de mayor captura fue el siguiente en el laguinho / cantina con $53,2 \%$. En el verano de 2008 fue capturado el $68,7 \%$ de los insectos, seguido por el otoño de 2008 con el $28,9 \%$, la primavera de 2007 con $2,4 \%$, y en lo invierno no hubo capturas. El análisis gráfica del número de capturas durante los meses sugiere la existencia de un pico de ocurrencia, en el medio del verano, lo que indica la existencia de factores climáticos capaces de regular la proliferación de fanídeos en la región.

Palabras clave: Campus de la Universidad; Moscas; Salud Pública.

\section{INTRODUÇÃO}

A fragmentação dos habitats naturais pelas ações antrópicas causam modificações profundas na dinâmica das populações de animais e vegetais, podendo acarretar isolamento e até extinção de espécies devido às interações ecológicas (SILVA, 2009). Por sua vez, o surgimento de ecossistemas artificiais, resultantes do processo de urbanização, gera novos habitats que passam a ser preenchidos por populações de espécies da fauna nativa, uma vez que esta já ocupava esses ambientes agora modificados, ou até fauna proveniente de outras regiões geográficas (FORATTINI, 2004). Essas espécies passam a se beneficiar do material orgânico gerado ou acumulado em atividades antrópicas como, por exemplo, algumas espécies de moscas. 
Os dípteros muscóides (as moscas) têm um papel ecológico essencial na natureza porque suas larvas facilitam a reciclagem de nutrientes pela fragmentação e modificação bioquímica da matéria orgânica em decomposição. Elas propiciam a melhoria do solo pela abertura de galerias quando se enterram para pupação, participam ativamente dos processos naturais de polinização, assim como carream microrganismos saprófitas essenciais aos ciclos biogeoquímicos e são responsáveis pela manutenção de diversas populações de animais insetívoros como pássaros e répteis (DELEITO, 2008 apud ODUM, 1983).

Por outro lado, as moscas podem tornar-se um problema quando suas populações aumentam muito, o que frequentemente acontece em regiões de clima mais quente, quando o seu desenvolvimento e a ovogênese são acelerados, propiciando o sincronismo de numerosas gerações diferentes em um mesmo local. Densidades populacionais aumentadas tendem a facilitar a dispersão e a invasão de domicílios e propriedades pelas moscas, causando problemas econômicos e de Saúde Pública (PRADO, 2003).

Este mesmo autor destaca que, dentre os dípteros muscóides, comumente chamados de moscas, somente cerca de 20 espécies estão mais intimamente associadas ao homem nas áreas urbanas, distribuídas por 10 famílias, sendo uma delas a família Fanniidae (Figura1).

FIGURA 1. Exemplo de mosca da família Fanniidae

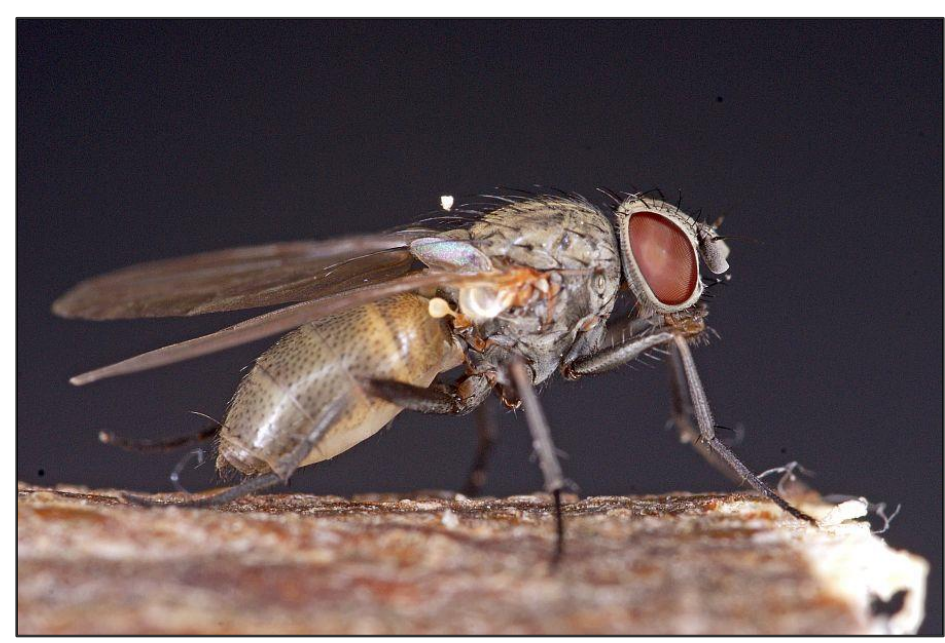

Fonte: http://www.naturspaziergang.de/Zweifluegler/Fannia_canicularis.htm 
A família Fanniidae é uma pequena família de Díptera, com aproximadamente 280 espécies descritas, em quatro gêneros, distribuídas em todas as regiões biogeográficas do mundo. Na região Neotropical são encontrados dois gêneros (com 84 espécies), que são os gêneros Euryomma Stein,1899 (com 11 espécies) e Fannia Robineau-Desvoidy, 1830 (com 73 espécies) (CARVALHO et al., 2003; COURI; CARVALHO, 2005) .

Os fanídeos, em sua maioria, são de tamanho pequeno, com coloração escura, amarronzada e coberta de múltiplas projeções penosas. As fêmeas são ovíparas, e seus ovos, de cor esbranquiçada, com formato oval alongado, eclodem em 24 horas. As larvas apresentam corpo achatado; completam seu crescimento em sete dias (JAMES; 1947; OLIVA, 1997).

As larvas apresentam hábitos saprófagos, encontrando-se em fungos, fezes, matéria mamíferos e himenópteros, inclusive associadas a tocas de mamíferos (CHILLCOTT, 1961; HOLLOWAY, 1985; MALLOCH, 1934 apud WENDT, 2009).

Os Fanniidae podem ser encontrados em vários tipos de ambientes. Desde zonas urbanas até áreas de matas. Em áreas de floresta são encontrados sobre arbustos, com os machos pairando formando pequenos enxames, enquanto as fêmeas permanecem na vegetação. Algumas espécies desta família estão intimamente associadas ao homem, como duas mais conhecidas por sua predileção por habitações humanas, a Fannia canicularis, comumente chamada de "mosca caseira ou pequena", e a Fannia scalaris de "mosca de latrina". Outras espécies também ocorrem no ambiente peri-domiciliar e se alimentam de fezes e matéria orgânica em decomposição, embora de pouca importância como vetores mecânicos de patógenos que ocorrem em fezes (CHILLCOTT, 1961; OLIVA, 1997; COURI; CARVALHO, 2005).

Destaca-se que a maioria das espécies estudadas até agora estão relacionadas a hábitos sinantrópicos e a material orgânico em decomposição, comportamento que faz considerá-las de importância sanitária e médica. Não obstante, a biologia e hábitos das espécies que ocorrem em áreas de floresta e regiões pouco habitadas e coletadas são pouco conhecidos (CHILLCOTT, 1961; WENDT, CARVALHO, 2009).

Portanto, os fanídeos podem apresentar grande importância econômica devido ao fato de algumas espécies apresentarem hábitos sinantrópicos e vetores 
de ovos da mosca do berne- Dermatobia hominis Linnaeus Jr (1781) e, também, estão relacionados com a decomposição de cadáveres de animais (GUIMARÃES; PAPAVERO, 1999; ESPÍNDOLA; COURI, 2004; WENDT; CARVALHO, 2007).

Tendo em vista o exposto acima, o presente trabalho tem como objetivo apresentar resultados obtidos no trabalho de capturas de moscas da família de Fanniidae intitulado "Fanídeos no campus da UNESP de Presidente Prudente", constituindo-se numa forma de contribuição da geografia para a compreensão do comportamento desses insetos e de sua importância para a saúde ambiental.

\section{MATERIAIS e MÉTODOS}

O presente trabalho foi realizado no campus da UNESP de Presidente Prudente, que ocupa uma área de aproximadamente 25 hectares (Figura 2), situado a cerca de um quilômetro do centro da cidade, na parte mais alta, e com expressiva cobertura arbórea, com predominância de plantas frutíferas como manga, goiaba, acerola, jabuticaba, dentre outras. Por esse ambiente circula diariamente um número significativo de pessoas (estudantes, funcionários e um público externo que participa das atividades de extensão ou utiliza de serviços prestados à comunidade). Essa população permanente e flutuante consome diversos tipos de alimentos e gera um volume de resíduos orgânicos, muitas vezes, mal acondicionados. Em vista disso, é preciso analisar a relação das condições ambientais da área de estudo e a presença de uma variedade de animais, aves e insetos, como é o caso das moscas. Uma vez que o campus universitário está localizado em um divisor de água e abrange as vertentes de duas microbacias, essa análise ganha relevância geográfica, fornecendo subsídios para o planejamento ambiental no espaço urbano do município. Dessa forma, o estudo privilegia noções espaciais relacionadas com a ocorrência de moscas, e abre a perspectiva de se avançar na reflexão a respeito da contribuição da geografia para a compreensão do comportamento desses insetos e da necessidade de seu monitoramento e controle para a melhoria da saúde ambiental (SEOLIN DIAS, FONSECA, GUIMARÃES, 2012). 
FIGURA 2. Localização do campus da UNESP de Presidente Prudente, São Paulo.

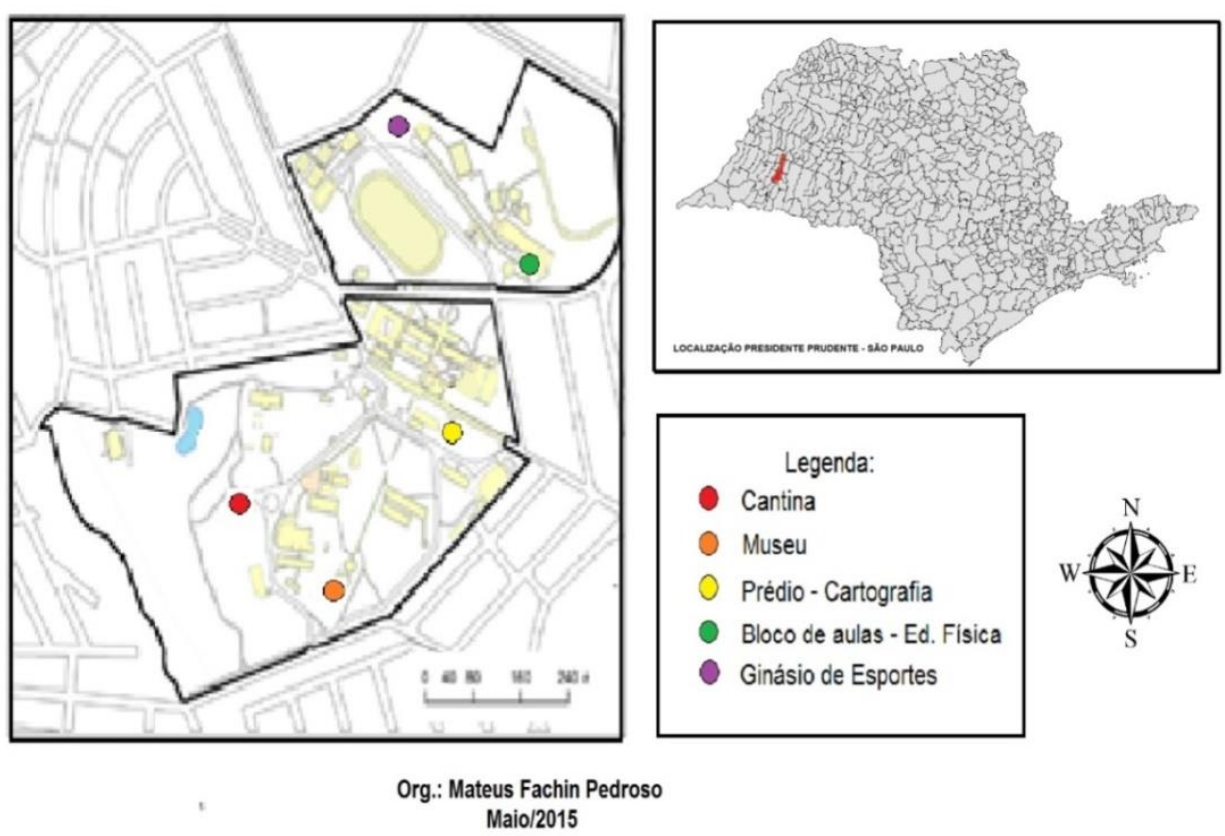

Organização da figura: Pedroso e Guimarães (2015).

As moscas foram capturadas no período de junho de 2007 a junho de 2008, com capturas semanais, totalizando 40 coletas. Para a captura dos insetos utilizouse de seis armadilhas confeccionadas com garrafas PET, de 2L, conforme modelo descrito por Ferreira (1978), e modificado por Seolin Dias (2008). Cada uma delas, contendo como atrativo aproximadamente $300 \mathrm{~g}$ de fígado bovino e carcaça de peixe, permaneceu exposta em árvores a uma altura de $1,0 \mathrm{~m}$ a 1,70 $\mathrm{m}$ durante cinco dias.

Os pontos de captura foram os seguintes: ponto 1, na faculdade de Educação Física; ponto 2, no Ginásio de Esporte; ponto 3, no Laguinho/cantina; ponto 4, no Museu e ponto 5 na Biblioteca. A escolha destes pontos de coleta garantiu a distribuição das armadilhas pelas vertentes das duas microbacias onde está localizado o campus universitário, assim como diferentes formas de uso do espaço (equipamentos esportivos, gabinetes de docentes e laboratórios de grupos de pesquisa, salas de aula e locais de alimentação), conforme a figura 3 da esquerda para a direita. 
FIGURA 3. Pontos de capturas das moscas no campus da UNEP de Presidente Prudente, SP.

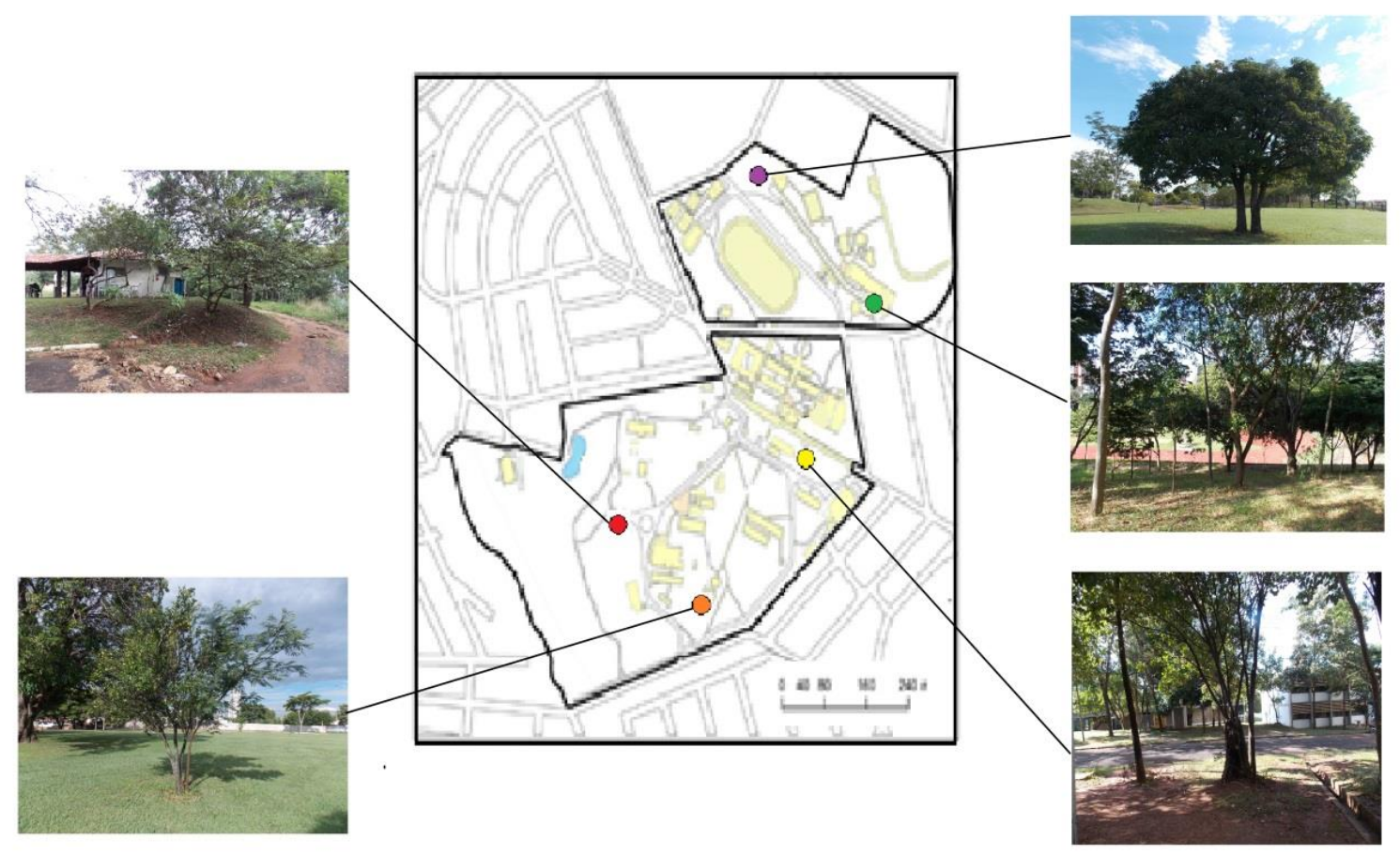

Fonte das figuras: Seolin Dias (2015). Organização da figuras: Pedroso e Guimarães (2015).

Para a escolha dos pontos de coleta, foi realizada uma análise das tipologias de uso, com a finalidade de entender quais áreas possuíam mais substrato que poderiam favorecer a proliferação das moscas, numa imersão para leitura da paisagem. As características do entorno dos pontos de coleta são observadas a seguir no Quadro 1: 
QUADRO 1 - Características dos pontos no campus da UNESP, Presidente Prudente, $\mathrm{SP}$.

\begin{tabular}{|l|l|}
\hline \multicolumn{1}{|c|}{ Ponto } & \multicolumn{1}{|c|}{ Característica } \\
\hline $\begin{array}{l}\text { 1 Departamento de } \\
\text { Educação Física }\end{array}$ & $\begin{array}{l}\text { Presença de composição arbórea diversa, próximo à pista de } \\
\text { atletismo e salas de aulas do departamento (Figura 5). }\end{array}$ \\
\hline 3 Laguinho/Cantina & $\begin{array}{l}\text { Grama ao entorno, pouca presença de composição arbórea e } \\
\text { ausência de resíduos (Figura 6) }\end{array}$ \\
\hline Presença da mata ciliar, área de deposição de resíduos orgânicos de \\
origem vegetal provenientes do campus e proximidade do restaurante \\
(Figura 7). Presença de resíduo orgânico, proveniente de alimentos \\
consumidos durante o período do dia. Estão presentes no entorno \\
deste ponto também substrato proveniente de árvores frutíferas \\
(Figura 8).
\end{tabular}

Fonte: Seolin Dias, Fonseca e Guimarães (2012).

Os insetos coletados foram transportados para o Laboratório de Geografia da Saúde da UNESP de Presidente Prudente para contagem e classificação, com auxílio de microscópio estereoscópico, e utilização de chaves dicotômicas especificas para cada família.

\section{RESULTADOS E DISCUSSÃO}

Foram capturados no total de 569 moscas da família Fanniidae, conforme a Tabela 1. 
TABELA 1 - Número de moscas da família Fanniidae, com seus respectivos locais de capturadas no campus da UNESP, Presidente Prudente, no período de junho de 2007 a junho de 2008.

\begin{tabular}{|l|c|c|}
\hline Locais de capturas & Abundância absoluta & Abundância relativa (\%) \\
\hline 1. Departamento de Ed. Física & 61 & $10,8 \%$ \\
\hline 2.Ginásio de Esporte & 35 & $6,2 \%$ \\
\hline 3.Laguinho/Cantina & 303 & $53,2 \%$ \\
\hline 4.Museu & 122 & $21,4 \%$ \\
\hline 5.Biblioteca & 48 & $\mathbf{8 , 4 \%}$ \\
\hline Total & $\mathbf{1 4 6}$ & $\mathbf{1 0 0} \%$ \\
\hline
\end{tabular}

Organização: Seolin Dias e Faria (2015).

No verão de 2008 foi que ocorreu maior predominância de moscas com $68,7 \%$ (391) seguido do outono de 2008 com 28,9\% (165), primavera 2,4\% (13) e no inverno não houve registro de insetos. Os dados referentes ao total de moscas capturadas, por mês de captura, estão ilustrados na Figura 4.

Figura 4. Total de moscas fanídeos capturadas em diferentes ambientes do Campus da Universidade Estadual Paulista, Presidente Prudente, 2007-2008.

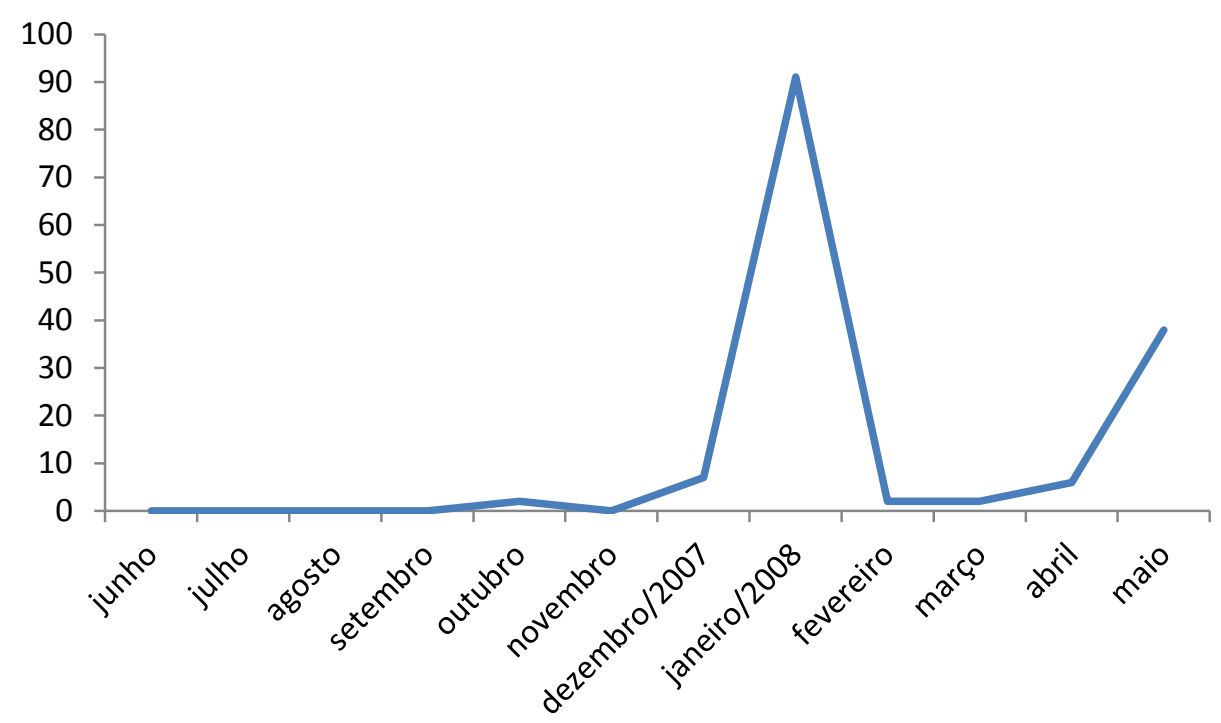

Organização: Seolin Dias e Faria (2015).

A análise gráfica relativa ao número de capturas ao longo dos meses sugere a existência de dois picos de ocorrência, um no início da primavera e outro no início do outono, sugerindo a existência de fatores climáticos capazes de regular a 
proliferação dos fanídeos na região. Reforçando Forattini (1962), os fatores climáticos principais, como a temperatura e a umidade, influenciam diretamente sobre a composição das comunidades de animais.

\section{CONSIDERAÇÕES FINAIS}

Como foi destacado na introdução, o levantamento da flutuação de moscas dentro do campus por meio da análise da distribuição espacial por pontos geográficos relevantes pode ser um instrumento de tomada de decisão a respeito do zoneamento de usos e do planejamento ambiental, tendo em vista que foram encontradas diferenças expressivas da frequência de moscas, ora explicadas pela presença de substrato orgânico, ora sem a presença deste.

Assim, observou-se que no ponto de coleta no entorno do laguinho/cantina ocorreu um pico na abundância de moscas. Tal condição pode estar relacionada com o fato de o local ter se transformado em depósito de material orgânico proveniente da manutenção dos jardins do campus, com grande concentração de galhos, folhas e frutas em decomposição. E, na cantina, a presença de resíduos orgânicos acumulados no local provenientes de alimentos consumidos no decorrer do dia.

Acredita-se, com base nos resultados obtidos, que o instrumento de coleta e as frequências observadas sugerem a necessidade de se dar continuidade a estudos semelhantes no campus, agregando novos conhecimentos da biogeografia e da análise ambiental, tendo em vista a possibilidade de ampliar a compreensão do comportamento desses insetos em diferentes áreas, para auxiliar no controle adequado de moscas sinantrópicas. Para isto, será preciso entender a correlação da frequência de moscas com as características geográficas locais (SEOLIN DIAS, FONSECA, GUIMARÃES, 2012).

\section{REFERÊNCIAS}

BROWN, E., N. A. et al. Generality of shear thickening in suspensions. Nature Mater: v. 93, p. 220 224, 2010.

CARVAlho, C. J. B. A. C. PONT; M. S. COURI.; D. Pamplona. A catalogue of the Fanniidae (Díptera) of the Neotropical Region. Zootaxa, 219: 1-32, 2003. 


\section{Periádica Eletranica \\ Fórum Ambiental}

da Alta Paulista
Volume 11, Número 08, 2015

\section{Saúde e Saneamento} Ambiental

CHILLCOTT, J. G. A Revision of the Nearctic Species of Fanniinae (Diptera: Muscidae).Canadian Entomologist., v. 92, n. 4, p. 295, 1961.

COURI, M.S.; CARVALHO, C.J.B. Catálogo das espécies de Fanniidae do Estado do Rio de Janeiro (Brasil), Biota Neotropica, v. 2, p. 223-231, 2005.

ESPÍNDOLA, C. B.; M. S. COURI. Fannia flavicincta Stein (Diptera, Fanniidae): a new vector of Dermatobia hominis (Linnaeus) (Diptera, Cuterebridae). Revista Brasileira de Zoologia, v. 21, p. 115-116, 2004.

ESPOSITO, M.C.; CARVALHO, F.S.Composição e abundância de califorídeo

$\mathrm{s}$ e mesembrinelídeos (Insecta, Díptera) nas clareiras e matas da base de extração petrolífera, Bacia 33 do Rio Urucu, Coari, Amazonas. In: II Workshop de Avaliação Técnica e Científica, Manaus. 2006.

FLETCHER, M. G.; AXTELL, R. C.; STINNER, R. E. Longevity and fecundity of Musca domestica (Diptera: Muscidae) as a function of temperature. Journal of medical entomology, v. 27, n. 5, p. 922-6, set. 1990. Disponível em: <http://www.ncbi.nlm.nih.gov/pubmed/2231628>. Acesso em: 12 ago. 2013.

FORATTINI, O. P. Entomologia médica, São Paulo, Editora da USP: São Paulo, 1962.

FORATTINI, O. P. Ecologia, epidemiologia e sociedade. 2ed. Artes Médicas: São Paulo, 2004.

GREENBERG, B. Flies and diseases. Ecology, classification and biotic association. Princeton: Princeton University, 1971, 856 p.

GUIMARÃES, J. H.; PAPAVERO, N. Myiasis in man and animals in the Neotropical Region. Bibliographic database. Editora Plêiade/Fapesp: São Paulo,1999, 308 p.

GUIMARÃES, J. H.; PRADO A. P.; BURALLI, G. M. Dispersal and distribution of three newly introduced species of Chrysomya Robineau-Desvoid in Brazil (Díptera: Calliphoridae). Revista Brasileira de Entomologia, v.23, p. 245-255, 1979.

HOLLOWAY, B.A. Larvae of New Zealand Fanniidae (Diptera: Calyptrata). New Zealand Journal Zoology, v. 11, p. 239-257, 1985.

IMBIRIBA, A.; IZUTANI; D. T.; MILHORETO; I. T.; LUZ, E. Introdução de Chrysomya chloropyga (Wiedemann, 1818) na região neotropical (Diptera, Calliphoridae). Arquivos Biologia Tecnologia, v. 20: p. 35-39,1977.

JAMES, M. T. The flies that cause myiasis in man. Washington: U.S. Department of Agriculture mis cellaneous publication, $631,175,1947$.

MALLOCH, J. R. Muscidae. In: Diptera of Patagonia and South Chile 7: 171-346, 1934.

MARCONDES, C. B. Entomologia médica, Rio de Janeiro, Atheneu, 2001, 432 p.

NUORTEVA, P. Synanthropy of blowflies (Díptera: Calliphoridae) in Finland. Annales Entomologici Fennici , v. 29, p. 1-49.1963.

ODUM, E.P. Ecologia. Guanabara Koogan: Rio de Janeiro,.1983.

OLIVA, A. Insectos de interés forense de Buenos Aires (Argentina). Primera lista ilustrada y datos bionómicos. Revista del Museo de Ciencias Naturales "Bernardino Rivadavia" e Instituto Nacional de Investigaciones de las Ciencias Naturales, Entomología (Argentina), v. 7, p. 13-59, 1997. 
PAGANO, M.; GAUVREAU, K. Princípios de bioestatística. 1. ed. São Paulo: Cengage Learning, 2011.

PRADO, A. P. Controle das principais espécies de moscas em áreas urbanas. 0 biológico, v. 65, p. 95-97, 2003.

SEOLIN DIAS, L.; FONSECA, E. S.; GUIMARÃES, R. B. Distribuição espacial de moscas sinantrópicas (Insecta, Díptera) no Campus da UNESP de Presidente Prudente, SP. Revista GeoAtos, v. 1, p. 43-53. 2012.

SILVA, M. M. Diversidade de insetos em diferentes ambientes florestais no município de Contriguaçu, Estado de Mato Grosso. 111f. Dissertação (Mestrado em Ciências Florestais e Ambientais) - Faculdade de Engenharia Florestal, Universidade Federal de Mato Grosso, Mato Grosso.2009.

WENDT, L. D.; CARVALHO, C. J. B. Taxonomia de Fanniidae (Diptera) do sul do Brasil - I: nova espécie e chave de identificação de Euryomma Stein. Revista Brasileira de Entomologia 51: 197204.2007.

WENDT, S. Domestic Violence in Rural Austrália, The Federation Press, Annandale, NSW., 2009. 